\title{
China Introduces Water Law to Protect Limited Water Resources
}

To complement the nation's continuous efforts to improve management of its water sector, China has drafted her first water law to tighten control over the protection and management of her limited water resources. The forthcoming water technologies exposition and congress, $\mathrm{Wa}$ terTech China, $88,{ }^{*}$ is an endorsement of China's determination to improve management of her water sector.

The Water Law draft was introduced at the 23rd meeting of the Sixth National People's Congress (NPC) Standing Committee held in November 1987 in Beijing. Qian Zhengying, Minister of Water Resources and Electric Power, said that such a law in the country is extremely urgent, emphasizing that the proper use and protection of China's water resources require tight controls. It is hoped that the new law will help to guard against disasters and build up a comprehensive management system of water resources.

China's total water resources are estimated at 2,800 thousand million cubic metres, but the amount of water available per caput is much lower than the world's average. Moreover, water resources in the country are so unevenly distributed that some areas are frequently plagued by crises of water shortages. China has only explored $17 \%$ of its water resources - an equivalent of only about half of the comparable activity of the United States.

Minister Qian said that, despite the considerable achievements which China has made in the utilization of water resources and prevention of disasters caused by water, many problems still exist in water resources protection and management. Some of the serious problems which she cited are the water shortages in Northern China, serious water pollution, overexploitation of underground water in many cities which has led to subsidence of land, and the irrational water-supply scheme still practised in the domestic, industrial, and agricultural, sectors. Qian remarked that such problems are impairing peoples' health and hindering economic production.

The Minister also said that the new law will call for an overall management plan for the exploitation and utilization of water in the country. The draft law stipulates that the exploitation and utilization of water resources should take into consideration many interlocking factors: water-

* See also the Important Prospect published on page 375 of this issue. $-\mathrm{Ed}$. supply, drainage, irrigation, fisheries, flood prevention, hydro-power projects, water transport, prevention of water- and soil-erosion, and protection of the ecological balance.

WaterTech China '88, the first international water technologies exposition and congress hosted by the People's Republic of China, is timely and well positioned to look broadly into the array of problems which are confronted by China's water industry, and to introduce the latest advanced foreign equipment and technologies, that seem urgently required by China. To an unprecedented degree the event in prospect has already won extensive high-level support from all the Chinese ministries and bureaus involved with water technology:

- Ministry of Urban and Rural Construction and Environmental Protection

- Ministry of Water Resources and Electric Power

- Ministry of Public Health

- Ministry of Agriculture, Animal Husbandry, and Fisheries

- Ministry of Geology and Mineral Resources

- Ministry of Chemical Industry

- State Bureau of Oceanography

- Central Patriotic Health Campaign Committee, Rural Water Supply Project Office

- China Research Institute of Environmental Sciences.

The event is organized by the Martlink Communications Group and the official hosts will include the China Water Supply Association, Institute of Water Supply and Wastewater, China Civil Engineering Society, the China National Water and Wastewater Equipment Information Centre, and the State Science and Technology Commission. Meanwhile more than 2,500 organizations throughout the country registered with the Management Committee to apply for attendance to the event. A series of study tours and plant visits have also been planned for international delegates, allowing them to improve their understanding of this vital sector of modern China.

MaNAGEMENT COMmiTteE-WaterTech China ' 88
c/o MartLink Communications Group
GPO Box 13477
5/F Fu House
7 Ice House Street, Central
Hong Kong.

\section{'Environ' - a Pesticide Impact Database}

The Pesticide Impact Section of the Overseas Development Natural Resources Institute has compiled a bibliographic computer database of books and scientific articles about the environmental side-effects of pesticides (including herbicides and fungicides) in the tropics. This database, called 'Environ', has been designed to provide a rapid and comprehensive information service freely to scientists, farmers, and agricultural administrators, living in developing countries and working for international development organizations.

Gathered within Environ is information which was previously widely scattered throughout the scientific literature. The wise use of such information will ensure that inefficient and environmentally damaging uses of pesticides are minimized. Topics covered in Environ include:

\footnotetext{
* pesticide toxicity to non-targets

* pesticide persistence and residues

* environmental fate of pesticides
}

* ecological impact of pesticides on non-target organisms:

- evidence of mortalities

- population changes

- sublethal effects (e.g. animal behaviour).

'Environ' can handle enquiries about the effect of pesticides on non-target organisms (including soils), after first specifying the pesticide (or pesticides), the target pest(s) or non-target organism(s), or a combination of these. The output consists of a list of references, each of which is followed by an indication of the contents of each paper and in some cases a relevant abstract. Depending on the request, we also attempt to synthesize the information that is available, to aid the enquirer. There are no plans at present to provide an on-line facility for external users.

HuMPHREY Q.P. CRICK,

Overseas Development Natural Resources Institute College House

Wrights Lane, London WB 5SJ

England, UK. 